\title{
Shrinkage and Strength Properties of Coal Gangue Ceramsite Lightweight Aggregate Concrete
}

\author{
Yunsen Wang $\mathbb{D}^{1}{ }^{1}$ Jingping Qiu, ${ }^{1}$ and Chao Zeng $\mathbb{D}^{2}$ \\ ${ }^{1}$ Key Laboratory of Ministry of Education on Safe Mining of Deep Metal Mines, Northeastern University, Shenyang, China \\ ${ }^{2}$ Department of Civil, Architectural and Environmental Engineering, Missouri University of Science and Technology, \\ Rolla, MO, USA
}

Correspondence should be addressed to Yunsen Wang; wangyunsen@mail.neu.edu.cn

Received 16 February 2020; Revised 17 April 2020; Accepted 30 April 2020; Published 15 May 2020

Guest Editor: Ana S. Guimarães

Copyright (c) 2020 Yunsen Wang et al. This is an open access article distributed under the Creative Commons Attribution License, which permits unrestricted use, distribution, and reproduction in any medium, provided the original work is properly cited.

It is a promising and effective method for waste treatment by using coal gangue to make lightweight aggregate concrete. However, lightweight aggregate concrete with low-density coal gangue ceramsite is prone to cracking during volume shrinkage, which limits its application in the construction industry. In an attempt to resolve the problem of cracking in shrinkage, this study investigated the effect of prewetting time and shrinkage reducing agents on shrinkage volume and concrete strength through a series of concrete shrinkage and strength tests. The experimental results show that shrinkage volume reduced at a prewetting time of $12 \mathrm{hrs}$ or with a $2 \%$ addition of D-230 polyether amine reductant. With the optimal conditions of 12 hrs prewetting time and $2 \%$ addition of the reductant, the concrete shrinkage volume significantly decreased with a negligible impact on its strength. Appropriate amount of shrinkage reducing agent and adjustment of prewetting time of coal gangue ceramsite are necessary to reduce the shrinkage rate and improve the stability of the specimen. This is of great significance to wide application of lightweight aggregate concrete with coal gangue ceramsite.

\section{Introduction}

Coal gangue is a kind of solid waste generated by the coal mining and washing. Long-term storage not only takes up space but also causes serious pollution and destruction of the surrounding environment [1-3]. The treatment and utilization of coal gangue has attracted the interest of many researchers [4] since the 1970s. Coal gangue has been widely used for power generation, the extraction of chemical products, and the creation of chemical fertilizers and ceramsite [5-9].

Coal gangue can be converted into low-density ceramsite aggregates, which can be used to make low-density coal lightweight aggregate concrete, usually with an apparent density $<1950 \mathrm{~kg} / \mathrm{m}^{3} \quad[10]$. There are three types of coal gangue ceramsites (CGC): self-igniting coal gangue, burning coal gangue, and coal gangue mixed with binder [11]. Utilizing coal gangue to make CGC instead of natural, ordinary aggregate can reduce coal gangue disposal and lead to a significant reduction in the consumption of natural aggregates in the construction industry.

Compared with ordinary concrete, lightweight aggregate concrete has many attractive characteristics, such as lower density, higher strength, better antiseismic performance, and so on [12]. Many studies have been conducted on the preparation and expansion behavior of this concrete (the densities not exceeding $1950 \mathrm{~kg} / \mathrm{m}^{3}$ ) in the presence of additives including carbon fiber, waste materials [13, 14], and reductants [15-21]. However, owing to the high water absorption and porosity, large volume shrinkage of lightweight aggregate concrete causes the formation of cracks. These cracks connect to flow paths for gases, water, and aggressive substances. It is harmful for the durability and compromise of the performance of concrete structures [13]. This limits its application in the construction industry to a large extent. Many attempts to tackle this problem have been made in LWAC. For reefs aggregate, Cheng et al. [22] studied the drying shrinkage behavior of the concrete with 
different moisture contents. It is found that increasing the moisture content significantly reduced its shrinkage rate and the concrete made of saturated reef aggregates showed good performance in reducing autogenous shrinkage. For saturated lightweight aggregate, Henkensiefken et al. [23] studied the effect of the amount of cementitious material on LWAC shrinkage and found that specimens with larger volume fractions of SLWA reduced its shrinkage rate. For fly ash-clay ceramsite, Wang et al. [24] studied the effect of ceramsite prewetting on LWAC autogenous shrinkage by using microstructural analysis of the concrete and found that moisture content had influence on the shrinkage but was not dominant. For the shale ceramsite, Gong et al. [25] verified that the presence of a reductant can reduce the drying shrinkage and autogenous shrinkage of the concrete, thus mitigating the cracking issue. These studies have shown that adjusting the prewetting time or addition of a certain amount of reductant can effectively suppress shrinkage of the concrete. However, for coal gangue ceramsite, systematic tests on wetting time and shrinkage reducing agents have not been reported in any prior study. Three problems remain: (1) the lack of a quantitative relationship between CGC prewetting time and concrete shrinkage, (2) the lack of a quantitative relationship between the amount of SRA used and concrete shrinkage, and (3) the lack of a quantitative understanding of the combined effect of lightweight aggregate prewetting time and SRA amount on volume shrinkage and concrete strength.

The present study is conducted to fill these research gaps by investigating shrinkage and strength properties of coal gangue ceramsite lightweight aggregate concrete. A series of concrete shrinkage and strength tests were undertaken for different CGC prewetting times and SRA doses, separately. Through these experiments, the effects of CGC prewetting time and SRA on concrete shrinkage and strength will be analyzed, and the results will provide effective guidance for solving the concrete shrinkage problem.

\section{Experimental Investigation}

2.1. Materials Preparation. Ceramsite is a main component of coal gangue ceramsite lightweight aggregate concrete and accounts for approximately $50 \%$ of its total volume. Its properties have significant influence on the performance of the concrete. The coal gangue ceramsite used in this study was produced by Chaoyang Hualong Kejian Co., Ltd, and its morphology is shown in Figure 1. This product has similar physical characteristics and particle size distribution to ordinary concrete, as seen in Tables 1 and 2, respectively. It is widely used for concrete testing experiments.

JEEFMINE ${ }^{\circledR}$ D-230 polyether amine, with an average molecular weight of approximately 230 , was used as a reductant. Limestone sand with a particle size ranging from $0.15 \mathrm{~mm}$ to $2.34 \mathrm{~mm}$ was used as a fine aggregate. Tap water was used in all experiments. In this study, the dose of the added reductant ranged from $0.5 \%$ to $1.0 \%$ while the watercement ratio ranged from $15 \%$ to $20 \%$.

The fraction of the coal gangue ceramsite with a particle size ranging within $9.5 \sim 16 \mathrm{~mm}$ was $87.8 \%$ (see Table 2),

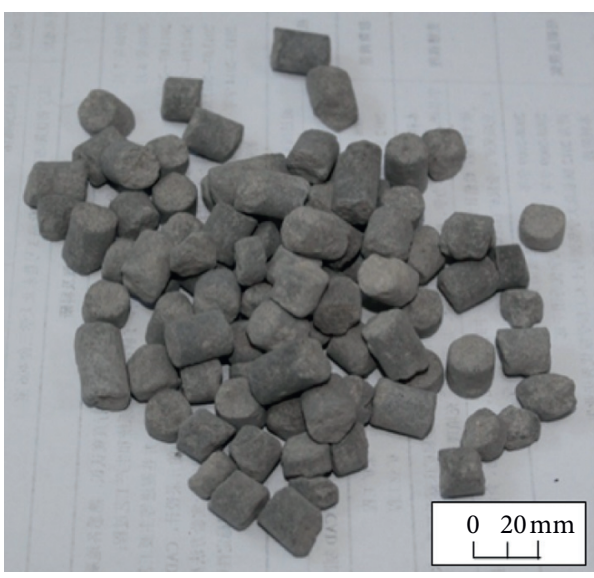

Figure 1: Morphology of the coal gangue ceramsite used in this study.

which meets the standard requirements for concrete materials (ASTM C330/C330M).

The cement used was $\mathrm{P} \bullet \mathrm{O} \bullet \mathrm{A} 32.5$ grade slag Portland cement. Its physical properties and chemical composition are shown in Tables 3 and 4, respectively.

The compressive strength at $28 \mathrm{~d}$ was $40.1 \mathrm{MPa}$, as shown in Table 3, and the loss on ignition was $1.06 \%$, as shown in Table 4 . The physical properties of the cement in terms of strength, chemical composition, and loss on ignition meet the quality requirements laid out in GB175-2007 entitled "General Portland Cement" and also meet the test requirements.

2.2. Design of Mixing Proportions for LWAC and CGC. In JGJ12-2006, which is entitled "Technical Regulations for Lightweight Aggregate Concrete Structure," the strength grade for structural LWAC is specified. In this test, LWAC was designed with compressive strength grade LC30. The initial mixing proportions are in Table 5. The following experiments are adjusted on the basis of the proportions.

\subsection{Preparation and Experimental Procedure}

2.3.1. LWAC Mixing and Curing. In the LWAC mixing process, the following stirring procedures were applied: first stir the cement, ceramic, and fine aggregate evenly, and then add the appropriate amount of water and superplasticizer (Figure 2). The mold size was $100 \mathrm{~mm} \times 100 \mathrm{~mm} \times 515 \mathrm{~mm}$, and the mixture well mixed by hand was placed in the mold to vibrate for $120 \mathrm{~s}$; after $24 \mathrm{~h}$, it was stripped for standard curing, and finally, the test was performed. Similarly, the following CGC prewetting procedure was followed: weigh the CGC; immerse the CGC in water for a certain period of time; drain the water to keep the saturated surface dry; and vibrate the mixture for $60 \mathrm{~s}$.

The specimens were cured at a temperature of $20 \pm 2^{\circ} \mathrm{C}$ and immersed in a saturated solution of $\mathrm{Ca}(\mathrm{OH})_{2}$. Then, concrete performance tests were carried out according to the GBT50081-2002 standard. 
TABLe 1: Physical characteristics of coal gangue ceramsite (based on GB/T 17431-2010).

\begin{tabular}{lccccc}
\hline Type of aggregate & Packing density $(\mathrm{kg} / \mathrm{m} 3)$ & Apparent density $(\mathrm{kg} / \mathrm{m} 3)$ & Compressive strength $(\mathrm{MPa})$ & Water absorption rate $(\%)$ \\
\hline CGC & 975 & 1730 & 35 & 5.07 & 6.50 \\
\hline
\end{tabular}

TABle 2: Particle size distribution for coal gangue ceramsite.

\begin{tabular}{lccrr}
\hline Sieve size $(\mathrm{mm})$ & 19.0 & 16.0 & 9.50 & \\
\hline Cumulative screen residue (\%) & 0 & 12 & 99.75 \\
\hline
\end{tabular}

TABLE 3: Physical properties of the cement.

\begin{tabular}{|c|c|c|c|c|c|c|c|c|}
\hline \multicolumn{2}{|c|}{ Setting time $(\min )$} & \multirow[t]{2}{*}{ Stability } & \multicolumn{2}{|c|}{$\begin{array}{c}\text { Flexural } \\
\text { strength } \\
(\mathrm{MPa})\end{array}$} & \multicolumn{2}{|c|}{$\begin{array}{l}\text { Compressive } \\
\text { strength } \\
(\mathrm{MPa})\end{array}$} & \multirow[t]{2}{*}{ Fineness $80 \mu \mathrm{m}$ sieve residue (\%) } & \multirow[t]{2}{*}{$\begin{array}{c}\text { Density } \\
\left(\mathrm{g} / \mathrm{m}^{3}\right)\end{array}$} \\
\hline Initial setting & Final setting & & $3 \mathrm{~d}$ & $28 \mathrm{~d}$ & $3 \mathrm{~d}$ & $28 \mathrm{~d}$ & & \\
\hline 204 & 312 & Qualified & 3.8 & 6.5 & 18.3 & 40.1 & 5.6 & 3.03 \\
\hline
\end{tabular}

TABLE 4: Chemical composition of the cement.

\begin{tabular}{lcccccc}
\hline $\mathrm{CaO}(\%)$ & $\mathrm{SiO}_{2}(\%)$ & $\mathrm{Al}_{2} \mathrm{O}_{3}(\%)$ & $\mathrm{Fe}_{2} \mathrm{O}_{3}(\%)$ & $\mathrm{MgO}(\%)$ & $\mathrm{SO}_{3}(\%)$ & Loss on ignition $(\%)$ \\
\hline 63.48 & 21.30 & 5.55 & 3.46 & 2.54 & 2.67 & 1.06 \\
\hline
\end{tabular}

TABLE 5: Mixing proportions for LWAC with CGC.

\begin{tabular}{lccccc}
\hline & \multicolumn{4}{c}{ Mix proportions $\left(\mathrm{kg} / \mathrm{m}^{3}\right)$} \\
Cement & Water & Sand & CGC & Apparent density $(\mathrm{kg} / \mathrm{m} 3)$ & 28 d compressive strength (MPa) \\
\hline 420 & 155 & 564 & 702 & 1749 & 38.4 \\
\hline
\end{tabular}

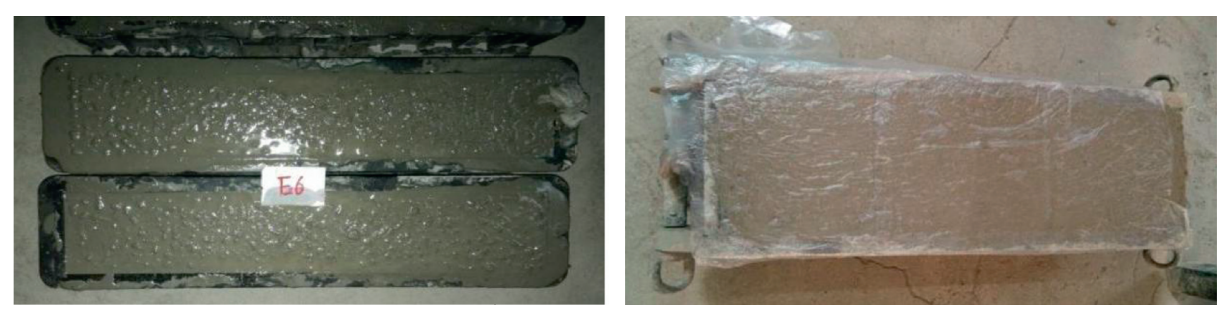

FIgURE 2: Forming a concrete specimen.

2.3.2. Compressive Strength Test for LWAC. The test machine was an NYL-200D. The instructions were as follows: place the specimen in the center of the lower press plate, keeping the center of the specimen in line with the center of the press plate (Figure 3). Start the press with the lower surface of the press plate facing upward. When the specimen is close to the upper plate and the upper pressure surface is in contact with the balanced test body, apply a uniform continuous load at a loading rate of $0.6 \pm 0.1 \mathrm{MPa}$. When the deformed specimen is close to destruction, stop adjusting the throttle of the press, and continue to load until destruction. Then, record the failure load. The compressive strength of LWAC was calculated as follows:

$$
f_{\mathrm{cu}}=\frac{F}{A}
$$

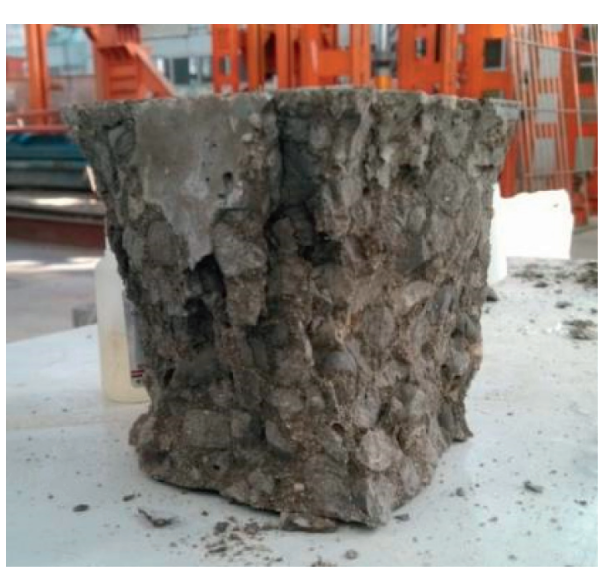

FIgURE 3: A picture after the specimen is damaged. 
where $f_{\mathrm{cu}}$ denotes the compressive strength of LWAC, MPa; $F$ represents the specimen failure load, $\mathrm{N}$; and $A$ is the specimen bearing area, $\mathrm{mm}^{2}$.

$F$ and $A$ are readily measured experimentally. From equation (1), the compressive strength for the test specimen size can be calculated. However, it must be noted that the product of this value and the size conversion factor (set to 0.95 in this study based on the standard set in GBT 500822009) is the final compressive strength for the standard size concrete.

2.3.3. Shrinkage Experiment for LWAC. The LWAC shrinkage test comes from GBT 50082-2009 entitled "ordinary concrete long-term performance and durability test method standards." After the specimen is modeled, it should be cured for $24 \pm 2 \mathrm{~h}$ with a membrane (Figure 4). The specimen's initial length $\left(L_{0}\right)$ is measured by an HSP-540 contraction expansion instrument, and then the specimen is placed in an environment in which the temperature is $20 \pm 3^{\circ} \mathrm{C}$ and the humidity is $60 \pm 5 \%$ at the proper time point to measure the specimen's length $\left(L_{t}\right)$. The resolution for the length measurement is $0.01 \mathrm{~mm}$.

The shrinkage rate for the specimen is calculated by using the following formula:

$$
\varepsilon_{\mathrm{st}}=\frac{L_{0}-L_{t}}{L_{b}}
$$

where $\varepsilon_{\mathrm{st}}$ is the shrinkage rate of the concrete at time $t$, $\mathrm{t}$ is the time elapsed after the initial length is measured, days; $L_{b}$ is the measured gauge of the specimen, that is, the distance between the inner sides of the concrete specimen, $\mathrm{mm} ; L_{0}$ is the initial length of the specimen, $\mathrm{mm}$; and $L_{t}$ is the length of the specimen measured at $t, \mathrm{~mm}$.

The shrinkage rates for the three specimens are averaged to calculate the shrinkage rate for the group, and the resolution of the final shrinkage rate is approximately $1.0 \times 10^{-6}$.

\section{Results and Discussion}

3.1. Effect of CGC Prewetting Time on Volume Shrinkage of $L W A C$. Five sets of LWAC were prepared according to the reference mixture proportions (see Table 5 for the mixture proportions). The selected prewetting times for the ceramsite are $0 \mathrm{~h}, 1 \mathrm{~h}, 6 \mathrm{~h}, 12 \mathrm{~h}$, and $24 \mathrm{~h}$. Three specimens were formed for each concrete test set. After the specimens were molded for $1 \mathrm{~d}$, they were demolded, and their initial length was determined according to the GBT 50082-2009 method. Thereafter, the shrinkage and strength of the specimens were measured at $1 \mathrm{~d}, 3 \mathrm{~d}, 7 \mathrm{~d}, 14 \mathrm{~d}, 28 \mathrm{~d}$, and $56 \mathrm{~d}$.

As seen from Figure 5, the shrinkage of LWAC develops gradually. LWAC shrinkage increases with time. Early on, the slope of the curve is large, indicating that the LWAC shrinkage rate is maximal. In the later stage, the LWAC shrinkage tends to level off. For example, the shrinkage rate for concrete at $3 \mathrm{~d}$ is more than $70 \%$ of the shrinkage rate at $28 \mathrm{~d}$.
It can be seen from Figure 6 that the shrinkage rate for LWAC decreases as the CGC prewetting time increases, but this decrease is not constant. When the prewetting time goes from $0 \mathrm{~h}$ to $1 \mathrm{~h}$, the shrinkage rate at $56 \mathrm{~d}$ (in Figure 6(b)) decreases by approximately $25 \times 10^{-6} \mathrm{~mm} / \mathrm{mm}$, while when the prewetting time goes from $12 \mathrm{~h}$ to $24 \mathrm{~h}$, the shrinkage rate at $56 \mathrm{~d}$ (in Figure 6(b)) decreases by only approximately $9 \times 10^{-6} \mathrm{~mm} / \mathrm{mm}$. This is because CGC water absorption increases rapidly in the early flooding stage, and the absorption rate reaches $5.07 \%$ at $1 \mathrm{~h}$. However, when the ceramsite is almost fully saturated after $12 \mathrm{~h}$, the water absorption rate for the ceramsite is only $0.38 \%$.

Therefore, the described approach is an effective way to reduce the drying shrinkage of LWAC for longer prewetting times because the prewet ceramsite contains a certain amount of water, and some of the water is gradually released in the late hydration process; thus, the relative humidity decreases slowly to compensate for the shrinkage. However, when the prewetting time exceeds $24 \mathrm{~h}$, the moisture content of the CGC has negligible variation, and the effect of the prewetting time on the shrinkage reduction rate is insignificant.

3.2. Effect of CGC Prewetting Time on the Strength of LWAC. Figure 7 shows that the prewetting time improves the mechanical resistance at 14 and $28 \mathrm{~d}$, and the only decrease is observed when the test is performed early (at $7 \mathrm{~d}$ ). This improvement is probably because the strength of the concrete and the cement stone depends on the interfacial adhesion of the aggregate and the cement stone. The denser the interface area of the structure, the greater the cohesive force and, hence, the higher the strength of the concrete. This trend probably also originates from a deficiency in the LWAC preparation due to a minor operation error. At $7 \mathrm{~d}$, as the moisture content of the CGC increases from 0 to $7.43 \%$ (from $\mathrm{C} 0$ to $\mathrm{C} 4$ ), its ability to absorb moisture from the cement slurry decreases, resulting in a decrease in the watercement ratio at the interface. The larger the water-cement ratio at the interface is, the greater the porosity is, so the early strength decreases. At $28 \mathrm{~d}$, with the further progression of the hydration reaction, the internal humidity of the cement slurry gradually decreases. The water return capacity increases with an increase in the prewetting time, so the cement in the interface area can be fully hydrated. This causes an increase in the density of the interface structure, so the compressive strength at $28 \mathrm{~d}$ increases. As seen in Figure 8, with an increase in the degree of ceramsite prewetting, the strength growth rate for LWAC also increases. The growth rate for LWAC $(\mathrm{C} 0)$ prepared with dry ceramic is $17.5 \%$, while the growth rate for LWAC (C4) is $35.9 \%$.

In the results of the preceding analysis, it can be seen that the strength of the LWAC decreases at a certain rate in the early stage after CGC prewetting, and the internal curing effect on the prewet ceramsite enhances its strength. This enhancement will increase with the degree of prewetting.

3.3. Effect of SRA on the Volume Shrinkage of LWAC. In the experiment, five groups of LWAC were prepared by 

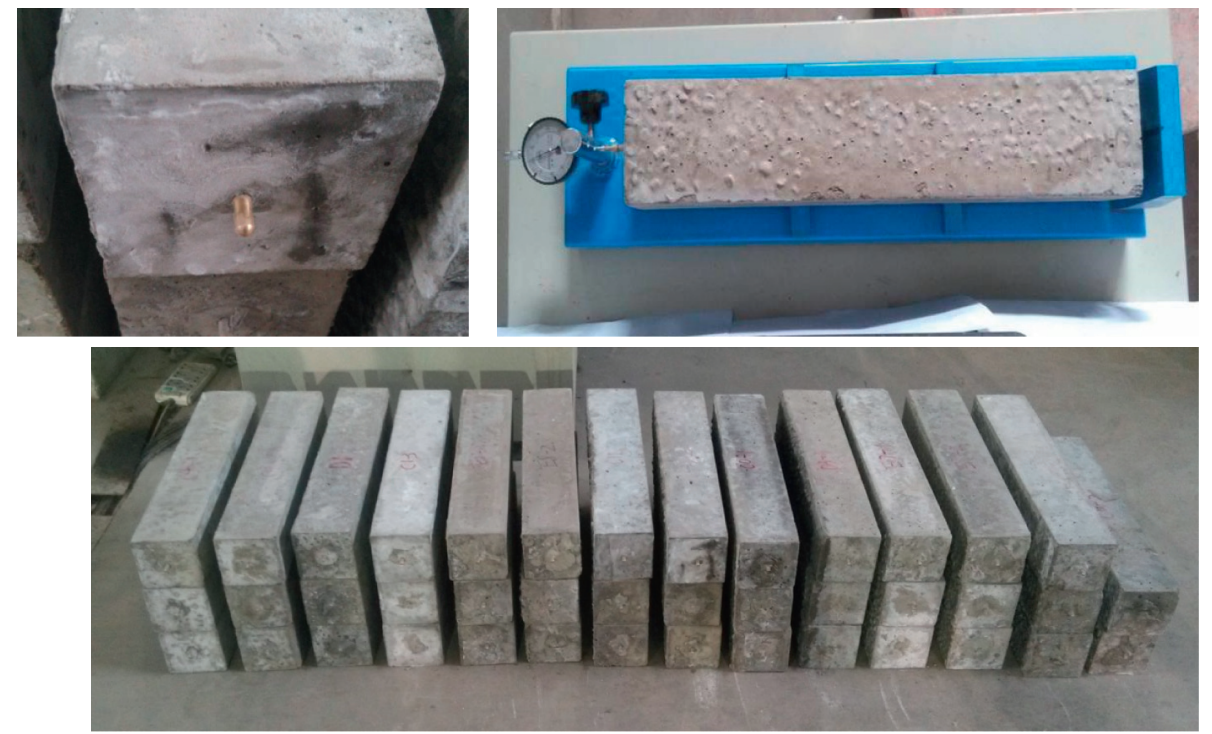

FIgURE 4: Shrinkage test device and concrete specimen.

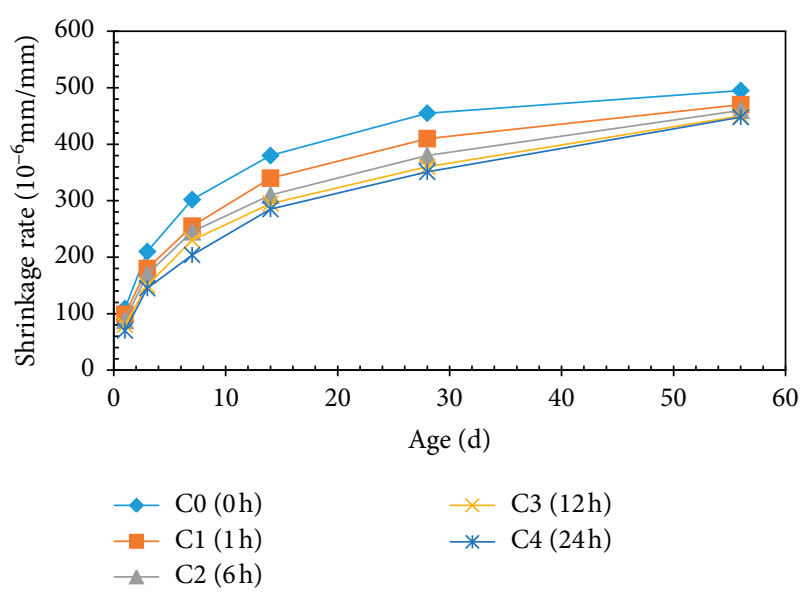

FIGURE 5: Effect of prewetting time on shrinkage rate for different CGC prewetting times.

adjusting the dose of SRA $(0 \%, 0.5 \%, 1.0 \%, 2.0 \%$, and $4.0 \%$ of the cement mass, respectively): the groups are denoted as $\mathrm{C} 0$, D1, D2, D3, and D4, respectively. The initial length of the specimens was determined by the GBT 50082-2009 method, and then the shrinkage was calculated at the following time points: $1 \mathrm{~d}, 3 \mathrm{~d}, 7 \mathrm{~d}, 14 \mathrm{~d}, 28 \mathrm{~d}$, and $56 \mathrm{~d}$.

It can be seen in Figure 9 that the addition of SRA considerably reduces the shrinkage of LWAC. With an increase in SRA, the LWAC shrinkage decreases gradually for each sample time point. For example, the shrinkage rates at $14 \mathrm{~d}, 28 \mathrm{~d}$, and $56 \mathrm{~d}$ for $\mathrm{C} 1$ are approximately $79 \%$, $82 \%$, and $79 \%$ of those for $\mathrm{C} 0$. In the case of $\mathrm{C} 1$, when the concentration of water is approximately $1.3 \%$, the cement paste internal capillary solution for the surface tension drops significantly, thereby reducing the negative pressure inside the gap and reducing the shrinkage of the specimen.

However, the shrinkage rate for LWAC instead decreases with an increase in SRA content. As shown in

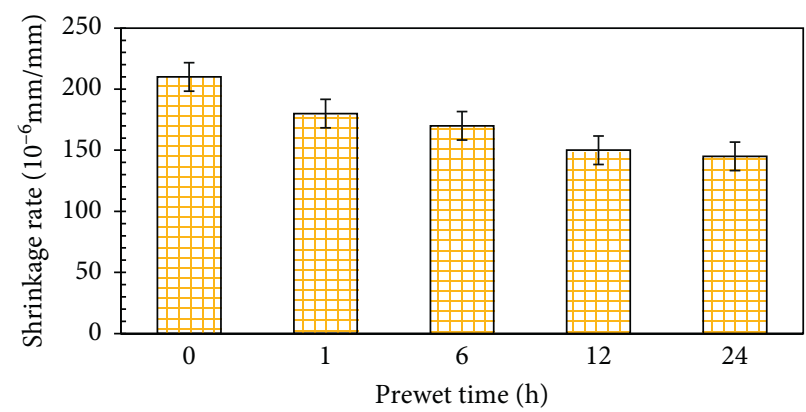

(a)

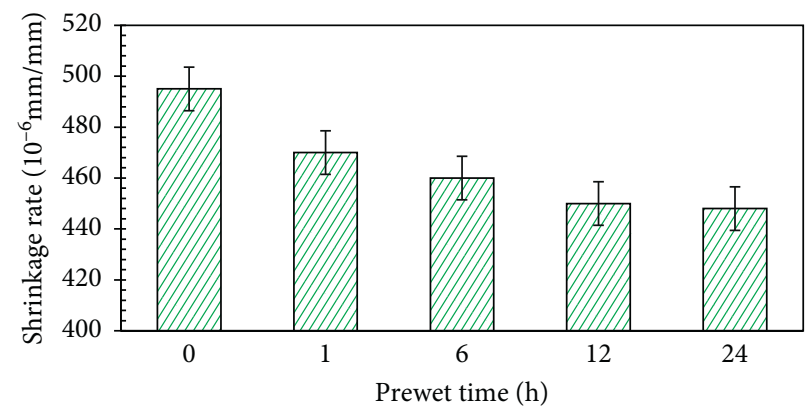

(b)

FIgURE 6: Shrinkage rate for different prewetting times (a) at $3 \mathrm{~d}$ and (b) $56 \mathrm{~d}$.

Figures $10(\mathrm{a})$ and $10(\mathrm{~b})$, the shrinkage rate for LWAC is influenced by the amount of SRA, which decreases monotonically with decreasing slope. A slower shrinkage reduction rate beyond $2 \%$ can be seen in both graphs. When SRA content increases from $2.0 \%$ to $4.0 \%$, the shrinkage at $3 \mathrm{~d}$ decreases by approximately $6 \%$, and the shrinkage at $56 \mathrm{~d}$ decreases by $3 \%$. This slower reduction after the $2 \%$ dose can be explained by the reduction of the solution surface tension. When SRA makes up over $2.0 \%$ of the cement, its concentration in the water is more than 


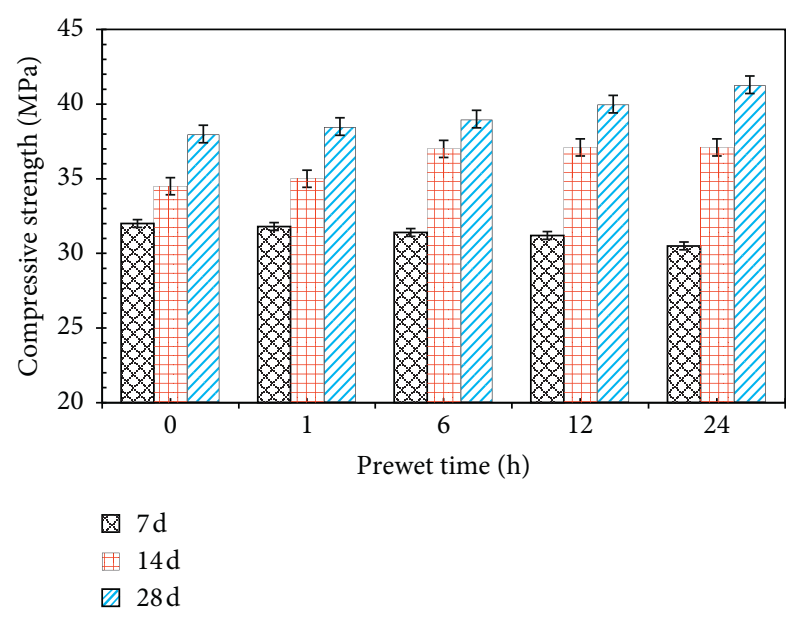

FIGURE 7: Effect of prewetting time of CGC on the compressive strength of the concrete.

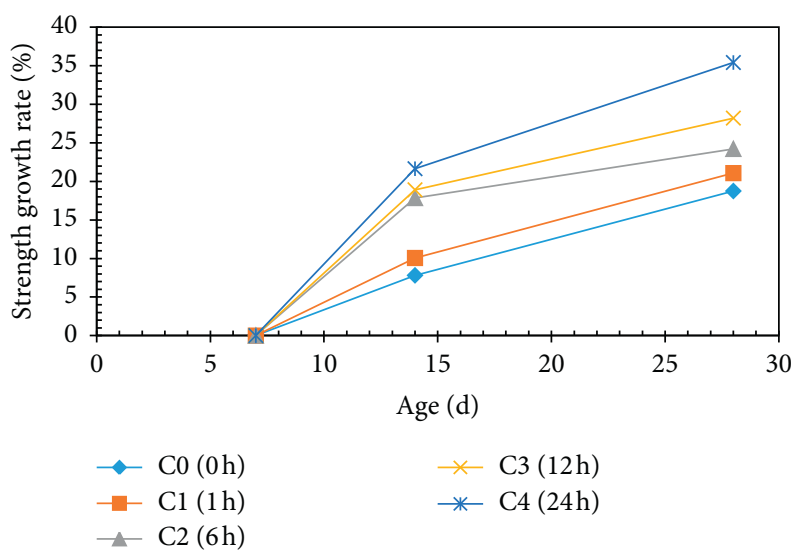

FIGURE 8: Strength growth rate for the concrete at different ages.

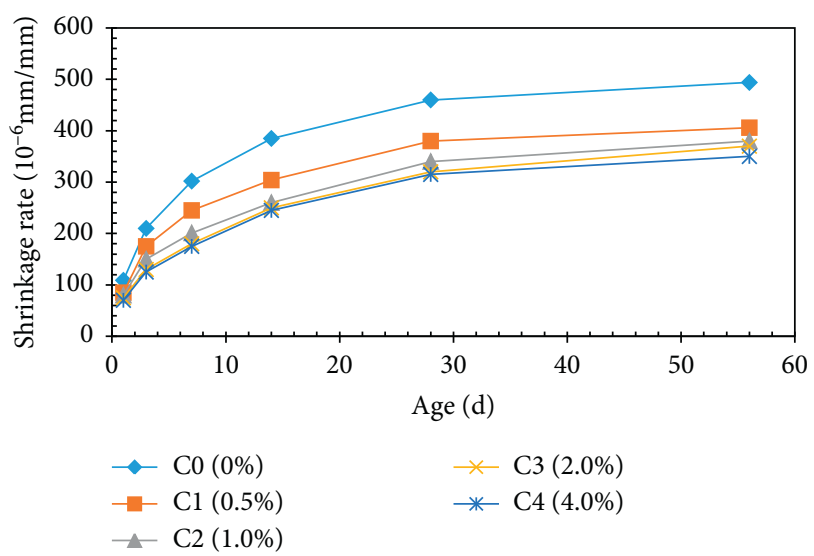

FIgURE 9: Effect of SRA dose on concrete shrinkage.

$5.0 \%$. Considering the dependence of the solution surface tension on the SRA, the reduction in surface tension slows after a certain dose, leading to a smaller effect of SRA on LWAC shrinkage. This finding is also consistent with the dose recommended in the product specification (1.0-3.0\% of the mass of the cement).

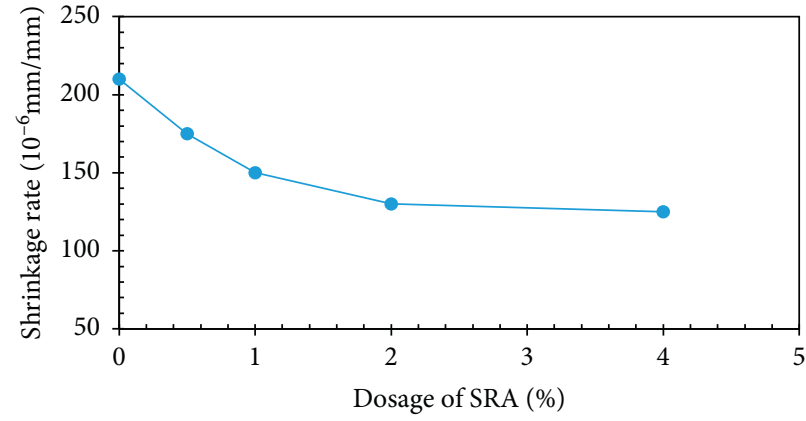

(a)

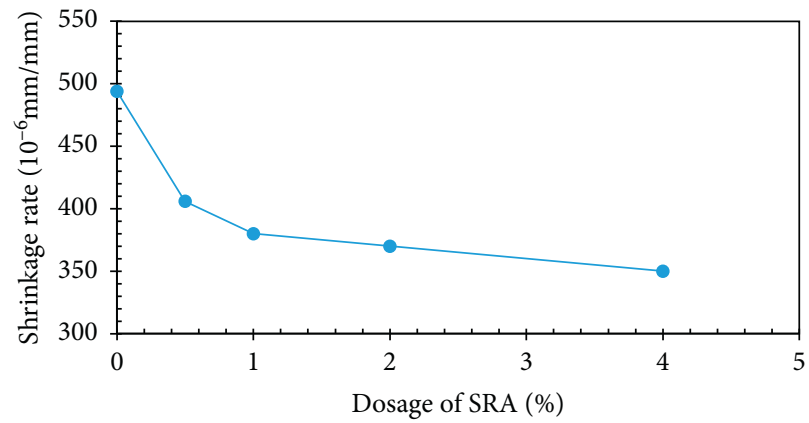

(b)

FIgURe 10: Concrete shrinkage with different doses of SRA (a) at $3 \mathrm{~d}$ and (b) $56 \mathrm{~d}$.

3.4. Effect of SRA on LWACStrength. As described above, five different percentages of SRA $(0 \%, 0.5 \%, 1 \%, 2 \%$, and $4 \%)$ were used in the construction of the cement test groups. Three sets of samples were prepared in each test group. After $1 \mathrm{~d}$ of stripping, they were placed in saturated $\mathrm{Ca}(\mathrm{OH})_{2}$ solution. According to the methods of GB/T 50081-2002 "Test method of mechanical properties of ordinary concrete," the compressive strength was measured at $7 \mathrm{~d}, 14 \mathrm{~d}$, and $28 \mathrm{~d}$. Then, the compressive strength of the concrete was measured.

Figure 11 illustrates that the SRA mixture has an adverse effect on the compressive strength of LWAC. With an increase in SRA, the compressive strength of LWAC gradually decreases. Compared to the reference group ( $0 \%$ SRA), the compressive strength for LWAC with 2\% SRA decreases by $6 \%$ and $3 \%$ at $7 \mathrm{~d}$ and $28 \mathrm{~d}$, respectively. When the SRA dose increases to $4 \%$, the compressive strength of the concrete decreases significantly, by $10 \%$ and $5 \%$ at $7 \mathrm{~d}$ and $28 \mathrm{~d}$, respectively. This is consistent with Rajabipour's study [26], which suggested that when the SRA dose is less than $2 \%$, there is no adverse effect on strength, whereas the strength of the concrete is reduced when SRA is increased to $5 \%$ of the cement content.

3.5. Combined Effect of SRA and Prewetting Time on LWAC Shrinkage. Figure 12 presents the conditions in which a combination of $2.0 \%$ SRA and different prewetting times $(0 \mathrm{~h}, 1 \mathrm{~h}, 6 \mathrm{~h}$, and $24 \mathrm{~h})$ are used. Based on the similar curve trends with and without SRA, shrinkage suppression can mainly be attributed to prewetting. It should be noted that, 



(a)

$$
\begin{aligned}
& \otimes 7 d \\
& \text { 目 } 14 d \\
& \square 28 d
\end{aligned}
$$

FIGURE 11: Effect of SRA dose on the compressive strength of concrete.

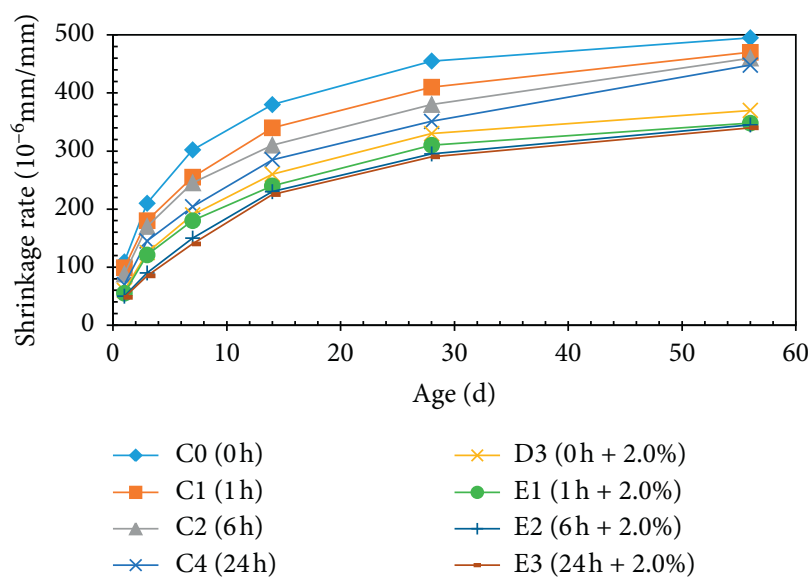

FIGURE 12: Effect of the prewetting time on concrete shrinkage with SRA incorporation.

since the relative ratio of water to cement in the experiment is $0.4 \%$, the concentration in the water is approximately $5.0 \%$ with $2 \%$ SRA, indicating an increasing concentration of SRA. Therefore, tension is reduced a small amount, which is able to prevent significant shrinkage.

Figure 13 displays a similar decreasing trend with respect to the prewetting time for the shrinkage rate in both scenarios. When the prewetting time extends from 0 to $1 \mathrm{~h}$, the shrinkage rate decreases markedly. However, when the prewetting time extends from $1 \mathrm{~h}$ to $12 \mathrm{~h}$, the variation in the shrinkage rate is subtle. The difference in shrinkage variation after $1 \mathrm{~h}$ can be clearly seen in the two graphs. The case without SRA has a relatively larger reduction compared to the other case.

More quantitatively, the shrinkage $(\mathrm{mm} / \mathrm{mm})$ for $\mathrm{C} 0$, $\mathrm{C} 1, \mathrm{C} 2$, and C4 (in Figure $13(\mathrm{a})$ ) at $56 \mathrm{~d}$ was $497 \times 10^{-6}$, $473 \times 10^{-6}, 463 \times 10^{-6}$, and $449 \times 10^{-6}$. Compared with the lightweight aggregate $\mathrm{C} 0$ reference, the shrinkage $(\mathrm{mm} / \mathrm{mm})$ of C1, C2, and C4 decreased by $24 \times 10^{-6}, 34 \times 10^{-6}$, and

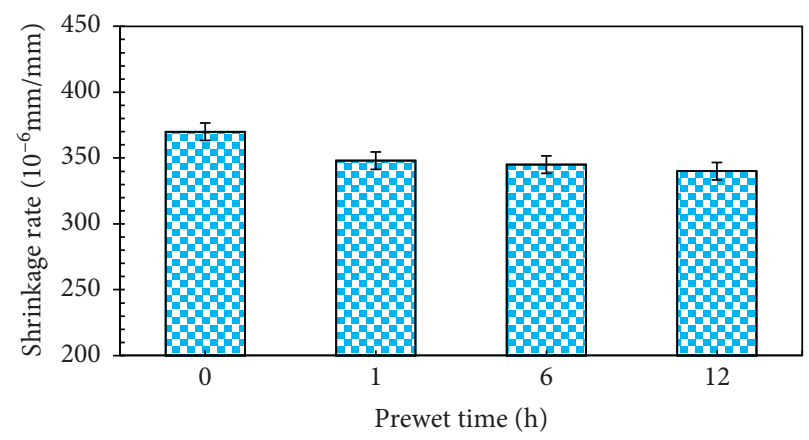

(b)

FIGURE 13: Shrinkage rate for concrete at $56 \mathrm{~d}$ (a) without SRA and (b) with SRA $(2.0 \%)$.

$48 \times 10^{-6}$, respectively. However, after the addition of SRA (in Figure 13(b)), the shrinkage $(\mathrm{mm} / \mathrm{mm})$ for D3, E1, E2, and E3 at $56 \mathrm{~d}$ was $368 \times 10^{-6}, 348 \times 10^{-6}, 343 \times 10^{-6}$, and $338 \times 10^{-6}$, respectively. Compared with the initial state of D3, the shrinkage $(\mathrm{mm} / \mathrm{mm})$ for E1, E2, and E3 produced a reduction of $20 \times 10^{-6}, 25 \times 10^{-6}$, and $30 \times 10^{-6}$, respectively. It can be seen that, after the induction of shrinkage and with the incremental change in prewetting, the result is not as pronounced as when internal curing alone is applied. This difference is probably due to the inclusion of SRA in the LWAC, which reduces the capillary solution surface tension. In the case where ceramsite water absorption is constant and the capillary diameter in the semisaturated state remains constant, the smaller the surface tension of the pore solution, the smaller the corresponding capillary tension drop. Thus, lower surface tension weakens the effects of shrinkage inhibition. This speculation remains to be confirmed in later research.

In this experiment, the effect of SRA on the shrinkage of LWAC under different dose conditions is also studied by using water-treated coal gangue ceramic. The water saturation time was $24 \mathrm{~h}$, and SRA concentrations of $0 \%, 0.5 \%$, $1.0 \%$, and $2.0 \%$ were selected for evaluation.

From Figures 14 and 15, it can be seen that the shrinkages $(\mathrm{mm} / \mathrm{mm})$ of D1, D2, and D3 at $56 \mathrm{~d}$ were $409 \times 10^{-6}, 381 \times 10^{-6}$, and $369 \times 10^{-6}$, respectively, when dry ceramic was used. These values are approximately $82 \%, 77 \%$, and $74 \%$ of that seen in the reference group C0. When saturated ceramsite was used, the shrinkages (mm/ 


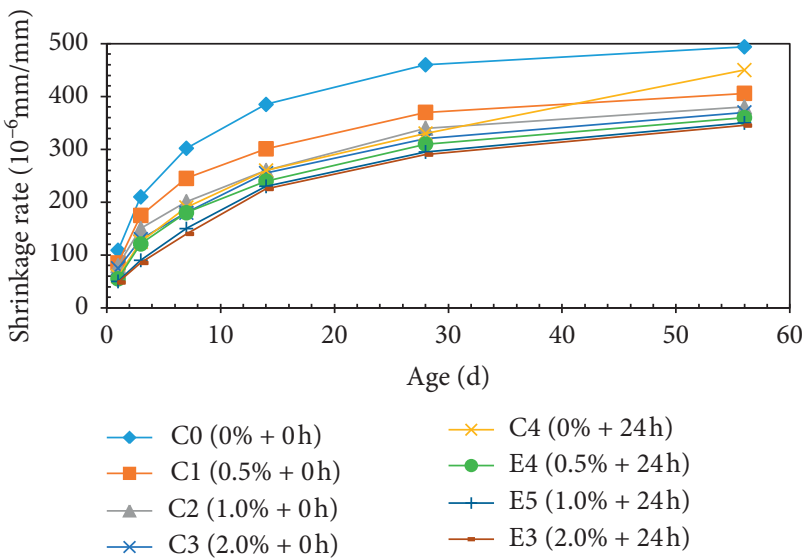

FIGURE 14: Effect of SRA dose on the shrinkage of the concrete for different prewetting times.

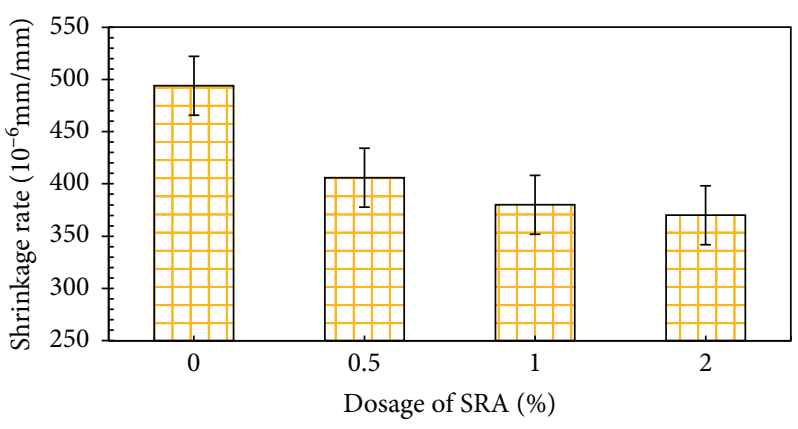

(a)

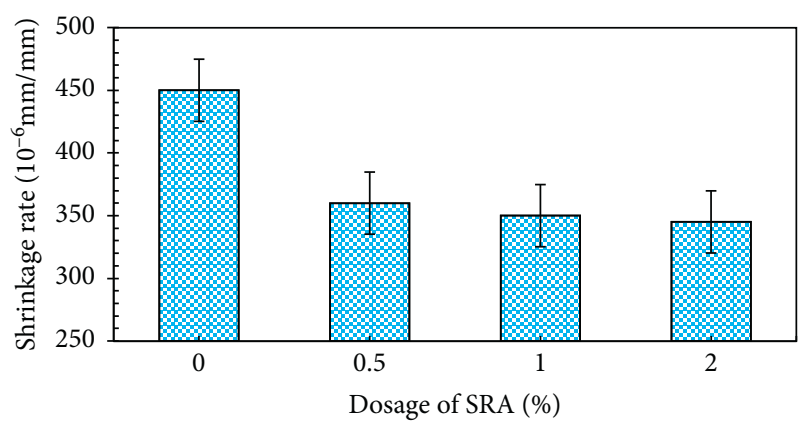

(b)

FIGURE 15: Shrinkage of the concrete with (a) drying and (b) CGC prewetting (24h) at $56 \mathrm{~d}$.

$\mathrm{mm})$ of E4, E5, and E3 were $382 \times 10^{-6}, 351 \times 10^{-6}$, and $338 \times 10^{-6}$, respectively. These shrinkages are $85 \%, 78 \%$, and $75 \%$ of those in reference group C4. Compared with the addition of SRA alone, as shown in Figure 15(a), the combined incorporation of SRA and prewetting of the ceramic, as shown in Figure 15(b), significantly reduces LWAC shrinkage. However, the effect of SRA increase on the drying shrinkage is not obvious, and the shrinkage rate in Figure 15(b) is lower than its counterpart in Figure 15(a).

In summary, compared with the prewetting of the ceramic or SRA alone, the use of both SRA and prewet ceramic composite together can significantly inhibit LWAC shrinkage, resulting in a significant "superposition" effect.

3.6. Combined Effect of SRA and Prewet Ceramic on LWAC Strength. Figure 16 displays the effect of SRA, prewetting time, and the combination of the two on the compressive strength of LWAC under dry curing conditions. In the early hydration stages, SRA and the internal curing compound have an unfavorable effect on LWAC strength, but it is smaller at the later stage and is slightly higher than that of the reference group C0. At the same SRA dose, compared with SRA alone, the use of prewet ceramsite results in higher LWAC strength. This increased strength is mainly due to the internal curing of ceramsite. The dense structure of the cement slurry interface area increases the concrete strength and ultimately compensates for the loss of strength caused by SRA-induced delay of cement hydration. In the combined case, with elapsed prewetting time, the late strength is enhanced to a certain extent.

In addition, at $7 \mathrm{~d}$, the LWAC strength in the combined case is lower than that in the reference group. However, the degree of reduction is much smaller than the sum of the drops observed when using SRA and internal curing individually. This result may be due to the addition of SRA. Under this condition, the shrinkage stress of the cement slurry decreases, and this decreased stress reduces the formation of microcracks and other defects, finally reducing the adverse effect on the strength. However, with an increase in SRA content, LWAC strength decreases, which indicates that the internal curing effect from prewetting the ceramic cannot completely eliminate the negative effect of SRA on strength when the SRA content is too large. 


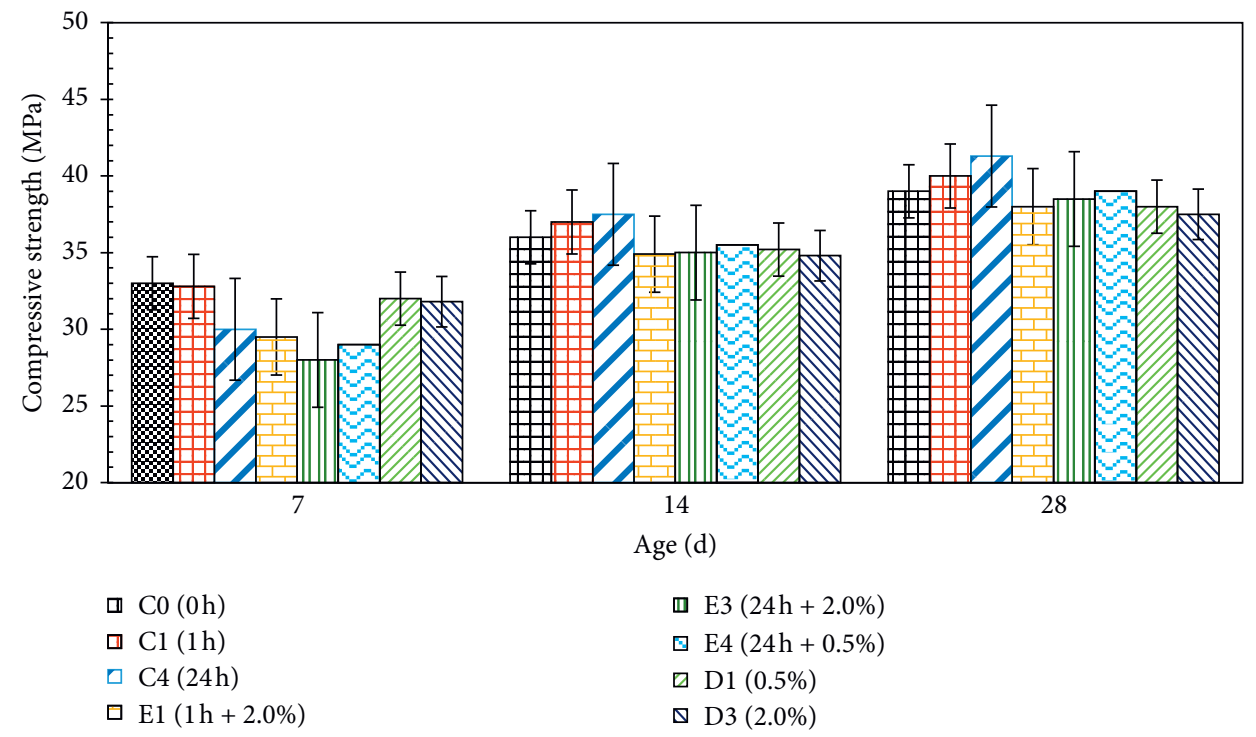

FIGURE 16: Influence of SRA, prewetting time, and a combination of SRA and prewetting time on the compressive strength of concrete.

\section{Conclusions}

In this study, the prewetting time of coal gangue ceramsite and shrinkage reducing agent were taken into account by laboratory experiments. The effects of the prewetting time and shrinkage reducing agent on the shrinkage volume and mechanical properties of LWAC are discussed. The results showed that prewetting time and shrinkage reducing agent have great influence on the shrinkage of lightweight aggregate concrete with coal gangue ceramsite. Appropriate control of prewetting time and shrinkage reducing agent in the sample preparation can increase strength of LWAC to meet the concrete strength standard and considerably reduce the shrinkage of concrete.

As prewetting time of CGC is prolonged, shrinkage volume of LWAC gradually decreases. For example, when ceramsite is initially prewetted, the shrinkage volume reduction is most notable. When CGC is prewetted for more than $12 \mathrm{~h}$, the effect of prewetting time on shrinkage volume reduction becomes insignificant. In addition, prewetting time also shows influence on strength. For example, after CGC prewetting treatment, the early strength (at $7 \mathrm{~d}$ ) of LWAC decreases. The late strength of LWAC increases and becomes higher than that without prewetting treatment.

The incorporation of SRA has a significant effect on shrinkage volume reduction of LWAC. For example, when SRA is $2 \%$ of the cement, shrinkage volume of LWAC at $56 \mathrm{~d}$ is reduced by approximately $26 \%$. When the SRA dose is large, an increase in the dose has less effect on shrinkage volume reduction. In addition, addition of SRA has an adverse effect on the compressive strength of LWAC. For example, when SRA makes up $2 \%$ or less of the cement, the effect of SRA on the compressive strength of the LWAC is small. When the dose increases to $4 \%$ of the cement, LWAC strength decreases significantly. The compressive strength decreases by $10 \%$ and $5 \%$ at $7 \mathrm{~d}$ and $28 \mathrm{~d}$, respectively.
The combined application of SRA and prewetting shows good and pronounced suppression of LWAC shrinkage. Specifically, the combined application has a certain influence on the early strength of LWAC. The late strength of the concrete enhances and effectively compensates for the adverse effect of SRA on strength.

Operation error in the preparation of LWAC, i.e., not mixing sufficiently, probably contributed to shrinkage and strength changes. The adverse effect of this operation error remains to be assessed and improved. It is suggested that the effect of different methods on the lightweight aggregate concrete with coal gangue ceramsite be presented by microstructure analysis. It can reveal the microscale mechanism of the dependence of concrete strength on prewetting time and shrinkage reducing agent.

\section{Data Availability}

The data used to support the findings of this study are available from the corresponding author upon request.

\section{Conflicts of Interest}

The authors declare that the research was conducted in the absence of any commercial or financial relationships that could be construed as a potential conflict of interest.

\section{Acknowledgments}

The authors gratefully acknowledge the financial support from National Science Foundation (51774066), the National Science and Technology Support Plan (2017YFC1503105, 2018YFC0604604, and 2019YFC1907201), Research and Development Project (Liaoning, 2019JH2/10300051) and Innovation Program for College Students Northeastern University, (201116 and 200060). 


\section{References}

[1] F. Salguero, J. A. Grande, T. Valente et al., "Recycling of manganese gangue materials from waste-dumps in the Iberian Pyrite Belt - application as filler for concrete production," Construction and Building Materials, vol. 54, pp. 363-368, 2014.

[2] C.-L. Wang, W. Ni, S.-Q. Zhang, S. Wang, G.-S. Gai, and W.-K. Wang, "Preparation and properties of autoclaved aerated concrete using coal gangue and iron ore tailings," Construction and Building Materials, vol. 104, pp. 109-115, 2016.

[3] D. Wu, Y. Hou, T. Deng, Y. Chen, and X. Zhao, "Thermal, hydraulic and mechanical performances of cemented coal gangue-fly ash backfill," International Journal of Mineral Processing, vol. 162, pp. 12-18, 2017.

[4] Y. Yao, Y. Li, X. Liu, H. Sun, S. Jiang, and C. Feng, "Performance and energy calculation on a green cementitious material composed of coal refuse," Clean Technologies and Environmental Policy, vol. 16, no. 2, pp. 281-290, 2014.

[5] J. Szczypa, J. Neczaj-Hruzewicz, and J. Sablik, "Some of properties of slime coatings in coal-gangue systems," Transactions of the Institution of Mining and Metallurgy, vol. 82, no. 802, pp. c167-c169, 1973.

[6] X. Querol, M. Izquierdo, E. Monfort et al., "Environmental characterization of burnt coal gangue banks at Yangquan, Shanxi province, China," International Journal of Coal Geology, vol. 75, no. 2, pp. 93-104, 2008.

[7] L. Haibin and L. Zhenling, "Recycling utilization patterns of coal mining waste in China," Resources, Conservation and Recycling, vol. 54, no. 12, pp. 1331-1340, 2010.

[8] H. Xiao, X. Ma, and K. Liu, "Co-combustion kinetics of sewage sludge with coal and coal gangue under different atmospheres," Energy Conversion and Management, vol. 51, no. 10, pp. 1976-1980, 2010.

[9] X. Liu, X. Zhuang, O. Font et al., "Influence of soil cover on reducing the environmental impact of spontaneous coal combustion in coal waste gobs: a review and new experimental data," International Journal of Coal Geology, vol. 85, no. 1, pp. 2-22, 2011.

[10] R. Demirboga, I. Orung, and R. Gul, "Effects of expanded perlite aggregate and mineral admixtures on the compressive strength of low-density concretes," Cement and Concrete Research, vol. 31, no. 11, pp. 1627-1632, 2001.

[11] J. Wang, Q. Qin, S. Hu, and K. Wu, “A concrete material with waste coal gangue and fly ash used for farmland drainage in high groundwater level areas," Journal of Cleaner Production, vol. 112, pp. 631-638, 2016.

[12] M. Aslam, P. Shafigh, M. Z. Jumaat, and M. Lachemi, "Benefits of using blended waste coarse lightweight aggregates in structural lightweight aggregate concrete," Journal of Cleaner Production, vol. 119, pp. 108-117, 2016.

[13] A. Hanif, Z. Lu, and Z. Li, "Utilization of fly ash cenosphere as lightweight filler in cement-based composites-a review," Construction and Building Materials, vol. 144, pp. 373-384, 2017.

[14] B. González-Corrochano, J. Alonso-Azcárate, and M. Rodas, "Production of lightweight aggregates from mining and industrial wastes," Journal of Environmental Management, vol. 90, no. 8, pp. 2801-2812, 2009.

[15] A. Ben Fraj, M. Kismi, and P. Mounanga, "Valorization of coarse rigid polyurethane foam waste in lightweight aggregate concrete," Construction and Building Materials, vol. 24, no. 6, pp. 1069-1077, 2010.
[16] P. Shafigh, H. B. Mahmud, M. Z. B. Jumaat, R. Ahmmad, and S. Bahri, "Structural lightweight aggregate concrete using two types of waste from the palm oil industry as aggregate," Journal of Cleaner Production, vol. 80, pp. 187-196, 2014.

[17] F. Colangelo, F. Messina, and R. Cioff, "Recycling of MSWI fly ash by means of cementitious double step cold bonding pelletization: technological assessment for the production of lightweight artificial aggregates," Journal of Hazardous Materials, vol. 299, pp. 181-191, 2015.

[18] F. Colangelo, R. Cioffi, B. Liguori, and F. Iucolano, "Recycled polyolefins waste as aggregates for lightweight concrete," Composites Part B: Engineering, vol. 106, pp. 234-241, 2016.

[19] F. Colangelo, F. Messina, L. Di Palma, and R. Cioffi, "Recycling of non-metallic automotive shredder residues and coal fly-ash in cold-bonded aggregates for sustainable concrete," Composites Part B: Engineering, vol. 116, pp. 46-52, 2017.

[20] A. Hanif, Z. Lu, Y. Cheng, S. Diao, and Z. Li, "Effects of different lightweight functional fillers for use in cementitious composites," International Journal of Concrete Structures and Materials, vol. 11, no. 1, pp. 99-113, 2017.

[21] M. I. Khan, M. Usman, S. A. Rizwan, and A. Hanif, "Selfconsolidating lightweight concrete incorporating limestone powder and fly ash as supplementary cementing material," Materials, vol. 12, no. 18, 2019.

[22] S. Cheng, Z. Shui, R. Yu, T. Sun, and X. Zhang, "Multiple influences of internal curing and supplementary cementitious materials on the shrinkage and microstructure development of reefs aggregate concrete," Construction and Building Materials, vol. 155, pp. 522-530, 2017.

[23] R. Henkensiefken, D. Bentz, T. Nantung, and J. Weiss, "Volume change and cracking in internally cured mixtures made with saturated lightweight aggregate under sealed and unsealed conditions," Cement and Concrete Composites, vol. 31, no. 7, pp. 427-437, 2009.

[24] X. F. Wang, C. Fang, W. Q. Kuang, D. W. Li, N. X. Han, and F. Xing, "Experimental investigation on the compressive strength and shrinkage of concrete with pre-wetted lightweight aggregates," Construction and Building Materials, vol. 155 , pp. 867-879, 2017.

[25] J. Gong, W. Zeng, and W. Zhang, "Influence of shrinkagereducing agent and polypropylene fiber on shrinkage of ceramsite concrete," Construction and Building Materials, vol. 159, pp. 155-163, 2018.

[26] F. Rajabipour, G. Sant, and J. Weiss, "Interactions between shrinkage reducing admixtures (SRA) and cement paste's pore solution," Cement and Concrete Research, vol. 38, no. 5, pp. 606-615, 2008. 